\section{INEZIL PENNA MARINHO: OPERAÇÕES HISTORIOGRÁFICAS NA EDUCAÇÃO FÍSICA} (1940-1958)

\author{
INEZIL PENNA MARINHO: HISTORIOGRAPHICAL OPERATIONS IN PHYSICAL \\ EDUCATION (1940-1958)
}
INEZIL PENNA MARINHO: OPERACIONES HISTORIOGRÁFICAS EN LA EDUCACIÓN FÍSICA (1940 - 1958)

\section{Antonio Sergio Francisco Oliveira*, Omar Schneider ${ }^{\star}$, Wagner dos Santos*, Amarílio Ferreira Neto*}

Palavras-chave Inezil Penna Marinho. História. Educação Física.

Keywords: Inezil Penna Marinho. History. Physical Education.

Palabras clave Inezil Penna Marinho. Historia. Educación Física.

\begin{abstract}
Resumo: 0 trabalho analisa parte da obra de Marinho com a intenção de dar visibilidade à sua compreensão sobre a História da Educação Física no Brasil. Com periodização entre 1940 e 1958, utiliza como fonte artigos publicados em periódicos e livros. A leitura dos dados mostra duas perspectivas historiográficas: a primeira é expressa na obra Contribuição para a história da educação física no Brasil e nos trabalhos apresentados em decorrência dessa publicação, que aproximam o autor dos princípios da Escola Metódica; a segunda, defendida por ele em 1958, segue outro caminho ao realizar uma associação entre História, Ciência e Arte, distanciando-se do positivismo como expressão de uma forma particular de fazer pesquisa histórica na Educação Física.
\end{abstract}

Abstract: The paper analyzes part of Marinho's work to show his understanding of Physical Education History in Brazil. Covering the 1940-1958 period, it uses articles published in journals and books as its sources. The data showed two distinct historiographical perspectives. The first one is expressed in the work Contribuição para a história da educação física no Brasil and in works presented as a result of this publication, linking the author to the principles of the Methodical School; the second one was advocated by him in 1958 and follows a different path by linking History, Science and Art, departing from positivism as an expression of a particular way of doing historical research in Physical Education.

\footnotetext{
Resumen: El trabajo analiza parte de la obra de Marinho con la intención de dar visibilidad a su comprensión sobre la historia de la Educación Física en Brasil. Abarcando un periodo que va de 1940 a 1958 utiliza como fuente artículos publicados en periódicos y libros. La lectura de los datos muestra dos perspectivas historiográficas: la primera se expresa en la obra Contribuição para a história da educação física no Brasil y en los trabajos presentados como consecuencia de esa publicación, que aproximan al autor a los principios de la Escuela Metódica; la segunda, defendida por él en 1958, sigue otro camino al realizar una asociación entre Historia, Ciencia y Arte, distanciándose del positivismo como expresión de una forma particular de realizar investigación histórica en la Educación Física.

*Universidade Federal do Espírito Santo. Vitória, ES, Brasil. E-mail: drasfo@ig.com.br Recebido em: 09/04/2014 Aprovado em: 09/12/2014 (c) (1) (8) Licence
} 


\section{INTRODUÇÃO}

A produção científica da Educação e da Educação Física já consagrou autores que representam 0 debate ocorrido entre 0 último quarto do século XIX e a primeira metade do século XX: Rui Barbosa, Fernando de Azevedo e Inezil Penna Marinho.

Conforme Bloch (2001), é inviável a escrita da História fora da compreensão das práticas do homem no tempo. Dessa forma, o estudo concebe Marinho como um intelectual engajado e, mesmo quando afirma que seus estudos são desinteressados, podemos perceber em suas narrativas o seu envolvimento com um projeto social. Projeto esse que procura escrever a História da Educação Física, destacando episódios, acontecimentos e documentos que trazem uma série de contribuições acadêmicas para a produção na área.

A pesquisa de parte da obra de Marinho tem por foco apreender as operações historiográficas ${ }^{1}$ praticadas pelo autor, o que possibilita caracterizar sua concepção de História. Nessas operações, conhecer o autor é determinar sua contribuição para os estudos na área da História da Educação Física brasileira, no período que se estende da segunda metade do século XIX à primeira metade do século XX.

Em nossas análises, optamos por entender a forma como Marinho organizou a produção sobre a temática da História da Educação Física e compreender o investimento feito para produzir a própria História da Educação Física no Brasil, forjando casos exemplares na intenção de nos informar o itinerário da Educação Física brasileira.

A periodização do estudo ocorre entre os anos de 1940 e 1958, o que se justifica pela intensa produção nesse período. Para tanto, consideramos algumas questões norteadoras: que apropriações Marinho fez sobre a História da Educação Física brasileira? Quais perspectivas históricas Ihe dão fundamento? Que discursos ele produz, tendo em vista as apropriações feitas sobre a perspectiva histórica?

Pelos usos que foram feitos da obra de Marinho, consideramos que ela passou a ser confundida com a própria memória da área e assim foi se constituindo ao longo das décadas em monumento da Educação Física e dos esportes no Brasil. "O monumento tem como característica o ligar-se ao poder de perpetuação, voluntária ou involuntária, das sociedades históricas (é um legado à memória coletiva) e o reenviar a testemunhos que, só numa parcela mínima, são testemunhos escritos" (LE GOFF, 2003, p. 526).

A alternativa que escolhemos para trabalhar as questões permite-nos estabelecer outras leituras para além das apresentadas por pesquisadores, como Nascimento (1997), Ferreira Neto (1999), Goellner $(2005,2009)$ e Melo (1998), que evidenciaram a importância de Marinho para o entendimento do cenário da Educação Física no Brasil.

A História Cultural nos possibilita entender a produção do autor, sobretudo a que discute a História da Educação Física brasileira, relacionando-a com o contexto em que ela se origina (formação profissional, espaços e lugares de atuação, táticas e estratégias de circulação). Assim, conhecer a obra desse intelectual facilita-nos compreender melhor a constituição das representações, que devem ser vistas como "[...] instrumento de um conhecimento mediador

1 No estudo, a escrita da História é compreendida como uma operação historiográfica, termo cunhado por Michel de Certeau (1982) para designar a prática social de narrar o passado. Para o autor, essa prática está ligada a um lugar social e, longe de ser apenas uma atividade técnica, está associada a instiuições regidas por leis silenciosas que circunscrevem um espaço adminstrado por regras próprias que permitem ou interditam temas de interesse dentro da área. 
que faz ver um objeto ausente através da substituição por uma imagem capaz de reconstituí-lo em memória e de figurá-lo como ele é" (CHARTIER, 1988, p. 20).

O autor sugere que esses processos devem romper com a ideia que "[...] dotava os textos e as obras de um sentido intrínseco, absoluto, único - o qual a crítica tinha a obrigação de identificar" (CHARTIER,1988, p. 27).

As representações destacadas por Marinho em suas operações históricas nos permitem perceber os lugares e espaços ocupados por ele de forma estratégica e/ou tática nas políticas de desenvolvimento da História da Educação Física dentro do quadro geral do campo da Educação. Assim, compreendemos que o lugar reclamado pelo autor para a História da Educação Física é o lugar reinvidicado pelo próprio como voz oficial da historiografia da área, capaz de falar com autoridade, com base em pesquisas sobre a configuração histórica desse espaço. Dessa forma é que empregamos as teorizações de Certeau (2004), estabelecendo que o lugar é o do próprio, do instituído, do conhecido, do identificável, enquanto o espaço é onde esse lugar é delimitado, utilizado, vivido, burlado e negociado. 0 que nos permite perceber a estratégica como um conceito que ajuda a compreender "[...] o cálculo [...] das relações de forças que se torna possível a partir do momento em que um sujeito de querer e poder [...] pode ser isolado" (CERTEAU, 2004, p. 99).

Com base nessas noções, analisamos que o lugar se institui estrategicamente, o espaço é praticado taticamente. Nesse sentido, a noção de tática se refere "[...] à ação calculada que é determinada pela ausência de um próprio. [...] a tática não tem por lugar senão o do outro" (CERTEAU, 2004, p. 100). Fundamentados nessas noções, discutimos, neste artigo, sobre a materialidade das práticas, dos objetos e de seus usos, construindo um modo de olhar e de interrogar a obra de Marinho.

Para dar a ver as representações que Marinho desenvolveu em sua operação historiográfica (CERTEAU, 1982), utilizamos, como fontes primárias, seus estudos sistematizados em forma de artigos e livros. Os periódicos foram selecionados com base em pesquisa realizada no Catálogo de periódicos de educação física (1930-2000), de Ferreira Neto et al. (2002). Os livros foram: Marinho (1943, 1952, v. 1 e v. 2, 1953, 1954, 1972, 1980).

\section{INEZIL PENNA MARINHO: DA PRESERVAÇÃO DO DOCUMENTO À PERSPECTIVA HIS- TORIOGRÁFICA}

Marinho (1943, p. 7) revela, na introdução de sua obra Contribuição para a história da educação física no Brasil, que o objetivo central de seu trabalho era colocar ao alcance de todos a documentação existente sobre a Educação Física e que, para isso, "[...] era preciso coordenar o maior número possível de dados e enfaixá-los num volume que facilitasse aos estudiosos do assunto qualquer informação". Destaca, ainda, que esse trabalho "[...] não representa o histórico da Educação Física no Brasil, mas apenas uma contribuição para 0 mesmo" (MARINHO, 1943, p. 7), já que não encontrara pesquisa similar desenvolvida até o ano de sua publicação, em 1943. Esse conteúdo fornece indícios de que Marinho trabalhava na busca de reunir documentos para preservar uma memória da Educação Física brasileira.

No entanto, a afirmativa de Marinho quanto à inexistência de estudos realizados anteriormente aos seus na área da Educação Física brasileira não reflete a vasta bibliografia 
a que ele recorreu. A título de exemplo, relacionamos os seguintes estudiosos citados pelo próprio autor: Fernando Azevedo (1920), Holanda Loyola (1939, 1940, 1941), Laurentino Lopes Bonorino (1931), Antonio de Mendonça Molina (1930, 1931, 1932, 1936) e Lourenço Filho (1938) (MARINHO, 1943).

Percebemos que, ao afirmar que não existia produção relacionada com a História da Educação Física no Brasil, ele pretende estabelecer a sua obra como a pioneira na área, tendo como objetivo, diferentemente do que afirma, o acúmulo de capital símbolico, ${ }^{2}$ ao afirmar que as fontes utilizadas eram as mais precisas e confiáveis para a construção do pensamento histórico da Educação Física brasileira.

Ao analisarmos um de seus estudos, das primeiras obras, podemos realizar aproximações do contéudo e da forma com a perspectiva da Escola Metódica. Ernest Lavisse, um dos signatários dessa corrente histórica, durante os anos 1890, na França, reuniu uma equipe de historiadores, visando à reconstituição do passado nacional. Em 1900, essa reconstituição influenciou a publicação da obra intitulada História da França. A utilização dessa obra é profícua para os nossos estudos, pois evidencia determinados princípios, muitas vezes implícitos, que norteiam os trabalhos dos historiadores da Escola Metódica. Em primeiro lugar, o título atesta que a pesquisa privilegia, como objeto, um estado-nação; em segundo, a periodização é articulada em função dos modelos de governos que servem de marcos cronológicos. Dentro da mesma ordem de ideias, aparecem os homens ilustres. Em terceiro lugar, acentuam-se os acontecimentos políticos, militares e diplomáticos. No entanto, os fatos econômicos e culturais são por vezes vistos com menos atenção e sempre colocados em posição subordinada, encarados no âmbito de uma estratégia política (BOURDÉ; MARTIN, 1983).

Essa escola histórica teve seus fundamentos difundidos na Europa e também no Brasil, visto que a produção historiográfica que norteava os estudos sobre a Educação Física brasileira era proveniente daquele continente, especialmente os chamados "métodos ginásticos", apresentados de forma evolutiva.

A Escola Metódica estava fundamentada num modelo de escrita historiográfica que pode ter influenciado a produção intelectual de Marinho, em 1943, quando ele apresenta o livro intitulado Contribuição para a história da educação física no Brasil.

Nesse livro, o autor dividiu o que denominou de ciclo evolutivo da Educação Física no Brasil da seguinte forma: Brasil Colônia - 1500-1822; Brasil Império - 1822-1889; Brasil República - 1889-1937. Este último período comporta uma subdivisão em três fases: a primeira de 1889 até 1930, a segunda de 1930 a 1937 e a terceira a partir de 1937.

Essa divisão não foi feita por Marinho de forma arbitrária, mas de acordo com os fatos que assinalaram verdadeiras etapas na história política brasileira, que serviam de marcos divisórios: a) a Independência do Brasil; b) a Proclamação da República; c) a Revolução de 1930; d) o Advento do Estado Novo (MARINHO, 1943).

No período de 1952 a 1954, Marinho publica a obra História da educação física e dos desportos no Brasil: Brasil Colônia - Brasil Império - Brasil República (documentário e bibliografia), mantendo a mesma característica daquela realizada em 1943.

2 Para Bourdieu (1990, p. 296), "[...] as lutas pelo reconhecimento são uma dimensão fundamental da vida social" e nascem da percepção de que existe um jogo a ser jogado, no qual "[...] está em jogo a acumulação de uma forma particular de capital" (BOURDIEU, 1990, p. 36). 
Em 1984, é lançado o livro História da educação física no Brasil, composto de 119 páginas, trazendo à tona as mesmas temáticas e estruturas dos textos presentes no livro editado em 1943 e nos volumes produzidos no período entre 1952 e 1954. Além de eliminar alguns tópicos das publicações anteriores, o autor consegue, com essa estratégia, sintetizar as informações, mantendo-se em circulação e visibilidade no campo científico.

Na composição da obra Contribuição para a história da educação física no Brasil (19421943), é preciso assinalar que, politicamente, o país atravessava um momento marcado por transformações, registradas por uma cultura com o objetivo de criar e confirmar o Estado Novo representado pelo governo de Getúlio Vargas, no período de 1937 a 1945.

Nascimento (1997, p. 26), a esse respeito, salienta:

A política cultural do Estado Novo visava criar uma memória coletiva, ou seja, recriar uma tradição nacional. Um dos caminhos possíveis para isso seria a divulgação da história do Brasil. Uma história construída com todo o conjunto de realizações acumuladas ao longo de um tempo, acrescida dos acontecimentos atuais, ou seja, o Estado Novo faria parte daquela história de forma enfática, como o Estado Novo, moderno, industrial, voltado ao desenvolvimento nacional, à cultura, à educação, ao crescimento do país.

Marinho construiu sua versão historiográfica agindo conforme a tendência que permeava os trabalhos históricos no Brasil, a exemplo dos produzidos por autores como Fernando Azevedo, Hollanda Loyola, Lourenço Filho e Aluizio Freire Ramos Accioly. Além disso, agia estratégica e taticamente de acordo com a política cultural regida pelo Estado Novo - governo Getúlio Vargas - que, a pretexto da recuperação do passado, era apresentada em textos históricos e resultava de uma cuidadosa pesquisa e coleta de dados, por meio das quais o historiador organizava e selecionava os textos que seriam usados por ele para a apresentação da História objetiva e verdadeira, não devendo emitir opiniões sobre ela.

Nas perspectivas desejáveis para aquela época, "o fazer história" significava deixar falar os documentos escritos, os ditos "documentos oficiais", que eram os que davam solidez e veracidadea otrabalho historiográfico. Desse modo, o autorbuscava estabeler um distanciamento do seu objeto, pois, de outra forma, esse perderia a prerrogativa da neutralidade. Porém, essa estratégia não o eximia de fazer críticas tanto à História da Educação Física no Brasil, quanto às políticas e reformas que introduziram a Educação Física no sistema educacional.

Embora Marinho fosse funcionário público do governo brasileiro no Ministério da Educação e Saúde, onde desempenhou a função de diretor da Divisão de Educação Física, do Departamento de Educação, não poupou críticas aos métodos ginásticos adotados no Brasil, em sua maior parte oriundos dos países europeus, e também aos modelos esportivos importados da Inglaterra e dos Estados Unidos.

As críticas e ponderações às políticas governamentais eram feitas por Marinho (1954) do lugar que ocupava como figura pública, distanciando-se do olhar da teoria aplicada ao estudo da História da Educação Física, que deveria ser realizado por meio de uma narrativa neutra e documentada, o que, em sua perspectiva, permitiria que os seus leitores tirassem as suas próprias conclusões.

Ao ser indagado sobre seu posicionamento crítico sobre governos e atores da política nacional, Marinho afirmou: 
As minhas críticas foram sempre aos atos e não às pessoas responsáveis pelo Ministério da Educação. Estas pouco me interessaram, pois as minhas preocupações se prenderam sempre aos problemas com que se debate a educação no Brasil. Quando os altos cargos do Ministério da Educação são ocupados por pessoas que dominam os seus mais importantes problemas e que, pelo equipamento de recursos de que são portadores, tenham possibilidades de melhorar a situação educacional do país, claro está que um raio de esperança nos ilumina e a chama do entusiasmo nos desperta do torpor contagioso que a todos mobiliza quando se verificam mudanças na administração ministerial (MARINHO, 1947, p. 5).

Apesar de realizar críticas ao governo, do qual participava ao assumir cargos públicos, ele estrategicamente fez uso do espaço para divulgar a sua proposta de compreensão da História da Educação Física no Brasil. E foi nesse contexto que o autor criou a sua obra.

Como vimos, a sua produção historiográfica pode ser filiada ao que é designado como Escola Metódica, que, segundo Karnal e Tatsch (2005), possui fundamento na perspectiva histórica designada como tradicional, preocupada com a "verdade" a partir de um olhar visto de cima e fundamentada em documentos oficiais, expressão máxima do acontecimento.

Bourdé e Martin (1983, p. 97), ao se referirem à Escola Metódica, afirmam que essa escola, também chamada "[...]mais abusivamente, 'positivista', aparece, manifesta-se, prolongase durante o período da Terceira República em França". Os seus princípios fundamentais estão expostos em dois textos-programa: $O$ manifesto, escrito por G. Monod, para lançar a Revista Histórica, em 1876, por G. Monod e G. Faginiez, e $O$ guia, redigido em intenção dos estudantes, por Ch. V. Langlois e Ch. Seignobos, em 1898. Os autores asseveram também que essa escola "[...] continua a dominar o ensino e a investigação em história nas universidades até os anos de 1940; e inscreve uma evolução mítica da coletividade francesa [...] na memória de gerações de estudantes até 1960" (p. 97).

Bourdé e Martin (1983, p. 97) ressaltam:

A escola metódica quer impor uma investigação científica afastando qualquer especulação filosófica e visando a objectividade absoluta no domínio da história; pensa atingir seus fins aplicando técnicas rigorosas respeitantes ao inventário das fontes, à crítica dos documentos, à organização das tarefas na profissão.

Essa perspectiva histórica tende a apresentar o objeto de estudo de forma linear, estática e fotográfica, quando se registra e se confunde com a história política e econômica, tematizando a história das grandes civilizações e apontando o poder dentro de uma visão macro e geral (CHARTIER, 1991). ${ }^{3}$

Le Goff (1993, p.156) entende que "[...] esse modo de fazer história se interessava quase exclusivamente por indivíduos, pelas camadas superiores da sociedade, por suas elites [...] e pelos acontecimentos [...] ou pelas instituições [...] dominados por essas elites".

$\mathrm{Na}$ perspectiva da Escola Metódica, o documento escrito e oficial é considerado o meio para reconstruir uma realidade e é utilizado como um recurso extremamente precioso na composição dos trabalhos de Marinho, por exemplo, os livros Contribuição para a história da educação física no Brasil: Brasil Colônia - Brasil Império - Brasil - República; História da

3 Ao citarmos Chartier (1991), Le Goff (1993) e Burke (1992), entendemos que o uso do conceito de História Tradicional pode ser associado à Escola Metódica, tendo em vista que esses estudiosos são partícipes da Nova História Cultural. Conceitua-se como tradicional tudo aquilo que vai de encontro ao novo. 
educação física no Brasil; e Rui Barbosa: o paladino da educação física no Brasil, nos quais o autor busca construir a grande História da Educação Física brasileira.

Em conformidade com essa perspectiva histórica, a política foi admitida para ser, essencialmente, relacionada com o Estado. Esse posicionamento oferece uma visão de cima, no sentido de que ela tem sempre se concentrado nos grandes feitos dos grandes homens, estadistas, generais, ou, ocasionalmente, eclesiásticos, esquecendo-se das personagens comuns e desconsiderando que essas também fazem parte da História (BURKE, 1992).

Percebemos que Marinho nesse primeiro momento procura fazer uma História não especulativa, extremamente linear e isenta de subjeividades, bem ao modo proposto pelo modelo historigráfico que acredita que, para ser válida, a ciência precisa ser neutra e objetiva. Exemplos dessa forma de narrar a História podem ser vistos nas obras escritas pelo autor em forma de artigos, organizados em livros, com seguidas reimpressões (1943, 1952-1954, 1980), em que ele registra a História com base nas fontes oficiais produzidas pelas instituições do governo. Desse modo, assumindo a voz dos vencedores como verdade, ou como meio para acessar a verdade histórica, a crítica documental é feita com o objetivo de validar as fontes como oficiais, provenientes de diferentes instâncias adminstrativas do Estado.

Apesar de ser possível filiar o autor à História Metódica, pela expressão de uma determinada metodologia utilizada na seleção, organização e usos das fontes, além da abordagem, roteiro e narrativa empregados para registrar a História da Educação Física, durante o período em que Marinho exercita a sua escrita histórica, ele também apresenta outras perspectivas historiográficas que fogem ao modo normativo da História chamada de tradicional.

\section{INEZIL PENNA MARINHO: HISTÓRIA, ARTE E CIÊNCIA}

Ao analisar algumas obras de Marinho, podemos perceber um autor que transita por outros caminhos, nos quais a História Metódica fica em um segundo plano para que ele produza outras narrativas sobre a História da Educação Física. Nesse momento enxergamos as tentivas de estabelecer diálogos com outras perspectivas não históricas, mas que se somam para que ele possa dialogar com os documentos. Esses diálogos são importantes para que 0 autor consiga desenvolver a História da Educação Física na interface com a Cultura, a História, a Ciência e a Arte.

Por meio dos diálogos entre a História, a Arte e a Ciência, Marinho se distancia dos princípios da Escola Metódica e, ao mesmo tempo, aproxima-se de outros modos de narrar a História, mas, como podemos perceber na citação a seguir, sem perder ainda uma ideia básica de que é possível buscar no passado bons ou maus exemplos para resolver os problemas do presente, ou do futuro:

A cultura histórica é a chave que permite ao homem moderno abrir todas as portas, a tábua que Ihe possibilita a decifração de todos os enigmas, a mágica fórmula que Ihe ensina os remédios de que necessita para os males que 0 afligem. A história oferece ao homem a oportunidade de equilíbrio científico-artístico, que deverá presidir às conquistas de seu espírito, à proporção que o mesmo se desenvolve (MARINHO, 1958, p. 127-131). 
De acordo com essa reflexão, constatamos uma ação de distanciamento dos princípios propostos pela Escola Metódica, mas não de todos, e a abertura para outras possibilidades interpretativas ao estabelecer o diálogo entre História e Cultura que, para ele, seria a chave que permitiria a análise das fontes. Aproximava-se, assim, do que vai denominar de oportunidade de equilíbrio, que é relacionar o fazer científico com o fazer artístico.

Não podemos restringir a obra do autor a apenas um modelo histórico; ele também buscava fazer experiências, deixando de apenas registrar acontecimentos e datas que serviriam a futuros historiadores da Educação Física. Dessa forma, é necessário ponderar as críticas e classificação realizadas por Melo (1998) sobre a perspectiva histórica de Marinho, pois ela não apenas reflete a forma de pesquisar e apresentar os dados propostos pela Escola Metódica, mas também indica distanciamentos do modelo original. Outra questão também diz respeito ao período em que o trabalho é desenvolvido. Apenas mais recentemente se faz a crítica documental, ${ }^{4}$ observando questões como o contexto e o lugar de produção das fontes, seus usos institucionais e o documento como monumento.

Nascimento (1997), ao analisar as críticas à obra de Marinho, percebe que não é em todos os livros que o autor usa os recursos teóricos da Escola Metódica. Conforme Nascimento (1997, p. 143), "[...] muito mais do que escrever uma história 'dita' positivista Marinho foi além dessa ação".

Ao estudar a obra de Marinho, percebemos um intelectual inquieto, que ocupa diferentes espaços e lugares, que busca variações temáticas sobre a Educação Física, aproximando-a da Filosofia, da Psicologia, da Sociologia e da História. O autor estava aberto a experimentações teóricas, revendo conceitos, criando novas reflexões sobre a História da Educação Física no Brasil e no mundo, principalmente a partir da segunda metade do século XX.

O ingresso de Marinho como professor da Escola Nacional de Educação Física e Desportos parece ser um marco divisor na sua produção sobre a História da Educação Física. A partir desse momento, sua obra segue outra direção, na qual busca aproximar a Educação Física da cultura brasileira, criticando a importação dos métodos ginásticos europeus e propondo o reconhecimento da capoeira como o método nacional de ginástica.

Essas ponderações ganham força no momento em que ele assume a cátedra de História e Organização da Educação Física e dos Desportos, abrindo mão da cadeira de Metodologia da Educação Física e do Treinamento Desportivo. Contudo, Marinho ressalta que a experiência com a disciplina Metodologia seria fundamental nos estudos que iria desenvolver no campo da História, pois, como ele próprio afirma:

A experiência ensinou-me que o conteúdo da cátedra de Metodologia da Educação Física é instável, renovando-se todos os anos, o que não permite sedimentação de cultura. E mais: com o decorrer do tempo, os conhecimentos se transferiram do campo metodológico para o domínio histórico. [...] a instabilidade do conteúdo dos programas de metodologia opõe-se à estabilidade dos assuntos pertinentes aos programas de História, que possibilitam ao professor neles cada vez mais se aprofundar. Concluindo, os conhecimentos de metodologia tendem, no tempo e no espaço, a transferir-se ao domínio da História; esta é a mais legítima herdeira daquela (MARINHO, 1958, p. 128).

4 Apesar de, em Marc Bloch (2001), na sua Apologia da história, ou O oficio do históriador (1949 - publicação póstuma), terem sido esboçados os principios de uma Crítica Documental, o uso dessa metodologia de análise ganha força com a Nova História Cultural, sobretudo nos estudos de Chartier (1988), momento em que se tornou mais comum entender que o documento não se reduz somente à sua dimensão textual. 
Em sua análise, é imprescindível o uso da metodologia, não havendo possibilidade de História sem método. É o método que permite a diferenciação entre 0 historiador e 0 artista. Contrariando suas próprias expectativas, o autor também pontua a possibilidade de a imaginação ser conjugada para o processo de compreensão da realidade, mas essa imaginação deveria estar subordinada à observação empírica, em seu caso, das fontes. Para Lacerda (2009), as teorizações de Comte não suprimiam a imaginação, mas a subordinava às leis da ciência, refreando a especulação e estimulando a lógica. ${ }^{5}$ Dessa forma, a História Metódica, ainda que extremamente racional para não sucumbir a uma acumulação estéril de fatos incoerentes, deveria permitir que, de forma artística, a lógica organizasse a dispersão dos dados. Seguindo essa ordem, Marinho afirmava em seu discurso:

Se a História tem por objeto a investigação e a exposição dos fatos históricos, em sua evolução no tempo e no espaço, apresenta ela a possibilidade de satisfazer às exigências do espírito científico e às necessidades artísticas da alma. Quando empreendemos a investigação dos fatos históricos, estamos submetidos a uma série de leis, a um método, a um procedimento que tem normas preestabelecidas; é, então, a ciência que nos domina. Mas ao expormos os resultados de nossas pesquisas, dando aos fatos uma interpretação puramente pessoal, penetramos nos domínios da arte, pois é evidente que estamos criando alguma coisa; aqui, a História perde o cunho científico para ganhar o artístico, o historiador deixa de ser o cientista para se tornar o artista (MARINHO, 1958, p. 131).

Ao propor a investigação e a exposição dos fatos, Marinho (1972) trabalha com 0 conceito de que a ciência é responsável por tratar do que é, de verificar fatos e descobrir, entre eles, relações constantes que se chamam leis. Encerra, assim, o que se poderá chamar julgamento de realidade. Ou seja, a produção do conhecimento histórico requer um método e as análises devem ser fundamentadas nas teorizações. Dessa forma, Marinho (1972, p. 3) entende que:

\begin{abstract}
O conhecimento científico é aquele que apresenta não apenas o fato, mas também as causas que o explicam; é o conhecimento certo e metódico, sistematizado, possibilitando ao homem a explicação dos fenômenos e, muitas vezes, a sua própria reprodução [...]. Diz-se que o conhecimento científico é geral, porque compreende sempre as leis que regem os fenômenos de que se ocupa, é verdadeiro porque explica os fatos pelas suas causas e leis, comprovadas pela experiência; é certo porque satisfaz às exigências da nossa razão, é metódico, porque todos os seus elementos são ordenados segundo as exigências lógicas; é sistematizado e unificado porque representa um conjunto cujas partes são concatenadas de forma a construir um todo único.
\end{abstract}

Observamos nessas passagens sua adequação à Escola Metódica. A escrita da História vai se tornando mais consciente e diretiva. Ao assumir a cadeira de ensino da História da Educação Física, o autor busca se tornar menos diletante. A metodologia e o domínio do método é o que acreditava que poderia tornar a pesquisa histórica um conhecimento científico, mas, ao mesmo tempo, reconhece a necessidade da Arte como meio para a exposição dos dados. A narrativa seria o momento em que 0 autor substituiria o cientista pelo artista, em que a subjetividade seria permitida como meio para a organização do conhecimento.

A possibilidade de dar vazão à interpretação, sem a mediação das fontes, segundo 0 autor, puramente pessoal, colocava 0 artista em confronto com 0 cientista, pois, segundo a lógica da Escola Metódica, essa ação interferiria na produção do conhecimento neutro e 
impessoal. Percebemos que Marinho está seguindo outro caminho, garantindo a cientificidade da História pelo emprego do método, da seleção, organização e uso das fontes, mas fazendo a leitura por meio das suas experiências e a exposição direcionada por seus interesses. Desse modo, diz ele que está produzindo uma "história nova", não tradicional, mas sem saber muito bem como classificá-la.

Podemos notar que, nesse momento, a preocupação de Marinho não era simplesmente compreender o conceito de História. Para ele, ao estudar/ensinar a História da Educação Física brasileira, era preciso ir além, era necessário o contato com a fonte original, possibilitando a informação primeira e evitando ruídos entre o instrumento e os comunicantes, não importando a memorização de fatos e datas. Desejava suscitar a investigação dos fatos, despertar 0 interesse pelo aproveitamento das experiências vividas por outros povos, buscava a interpretação consciente dos dados oferecidos à sua razão (MARINHO,1958).

Já sentia a necessidade de uma cuidadosa revisão das fontes de informações, responsáveis pelos conhecimentos que, há muitas décadas, vinham sendo transmitidos e retransmitidos, por intermédio, quase sempre, de uma série de traduções. Era preciso corrigir conceitos que se haviam erroneamente difundido, interpretações frágeis, que não resistiam a uma análise mais profunda ou a uma crítica mais severa [...] (MARINHO, 1958, p. 135).

A necessidade expressa por Marinho de preservar as fontes já era manifestada em sua obra Contribuição para a história da educação física no Brasil, ressaltando a importância das fontes para se organizar a história da Educação Física brasileira, apontando:

[...] a pobreza dos nossos arquivos e mesmo a falta de documentação a respeito do assunto até há bem pouco tempo sem importância para os poderes públicos [e] a dispersão das fontes informativas muito dificultam qualquer tentativa que se faça a esse respeito (MARINHO, 1953, p. 7).

Essa importância dispensada à fonte, observada sob as perspectivas da Nova História, é evidenciada por Bloch, que não entende a fonte como algo acabado, pois, segundo ele, "[...] os textos ou os documentos arqueológicos, mesmo os aparentemente mais claros e mais complacentes, não falam senão quando sabemos interrogá-los" (BLOCH, 2001, p. 79).

0 autor ainda considera as fontes como recurso primordial para a compreensão do homem, pois tudo que se produz e que se consome é realizado em função do ser humano, e o estudo detido das fontes pode ser favorecido pela "[...] diversidade dos testemunhos históricos [que] é quase infinita. Tudo que o homem diz ou escreve, tudo que fabrica, tudo que toca pode e deve informar sobre ele" (BLOCH, 2001, p. 79).

Em Marinho (1958), a História está ligada intrinsecamente ao trabalho do pesquisador. $\mathrm{Na}$ verdade, o historiador, antes de narrar os acontecimentos pelos quais está interessado, é um investigador, um pesquisador em busca de conhecimento.

Marinho associa História à Arte, todavia, no momento em que produz a análise sobre a importância do método para a História, ele diferencia o papel do historiador do papel do artista. Nesse ponto, destaca o cuidado que devemos ter com a interpretação pessoal daquilo que analisamos, mostrando que cabe ao historiador analisar, e, ao artista, a interpretação pessoal. Portanto, suas conclusões deveriam fazer uso desses dois recursos, para que de um lado não fosse apenas um compêndio de datas e fatos, mas de outro não se convertesse em ficção. Assim, Ciência e Arte se regulariam para produzir a narrativa histórica que seria empregada na escrita da História da Educação Física. 


\section{CONSIDERAÇÕES FINAIS}

Estudando a formação, atuação e produção de Marinho, observamos uma perspectiva de História que, tendo como base sua obra Contribuição para a história da educação física no Brasil e os trabalhos apresentados em decorrência dessa publicação, evidencia uma aproximação com os princípios da Escola Metódica.

Dada a forma de organizar e apresentar os documentos, assim como a ausência de análises, Marinho, em um primeiro momento, deixa transparecer a ideia de que as fontes falam por si, não sendo necessário analisá-las e interrogá-las, o que marca seu modo de produção historiográfica.

Quando analisamos a perspectiva de História defendida por ele já em 1958, percebemos um afastamento das bases conceituais que dão sustentação à Escola Metódica. Nesse caso, o autor faz uma associação entre História e Arte, destacando que cabe ao historiador desconfiar das fontes e problematizá-las, indicando rigor no uso de metodologias e nas análises.

Em função das definições projetadas por Marinho, a partir do período de inserção na Escola Nacional de Educação Física, observamos que o autor se aproxima de outra perspectiva histórica. Buscamos, nesse caso, compreender esse conceito de História, bem como analisar outros textos por ele produzidos que pudessem estabelecer uma correlação com essa nova perspectiva.

Outros aspectos da obra de Marinho ainda precisam ser visitados, como a relação que estabelece entre as teorias educacionais de seu tempo para projetar uma Educação Física com base na cultura brasileira, principalmente de matriz africana. $\mathrm{O}$ autor, a partir da década de 1940, busca conceituar a Educação Física utilizando diferentes conhecimentos oriundos tanto das Ciências da Natureza, como das Ciências Humanas e Sociais, com foco especial na Biologia, na História, na Sociologia, na Antropologia, na Psicologia e na Filosofia. Assim, Marinho ultrapassa o restrito entendimento anatomofisiológico de Educação Física e adota um conceito ampliado, designado por ele de biopsicológico e sociofisiológico.

\section{REFERÊNCIAS}

BLOCH, Marc. Apologia da história: ou o ofício do historiador. Rio de Janeiro: Jorge Zahar, 2001.

BOURDÉ, Guy; MARTIN, Hervé. As escolas históricas. 2.ed.. Sintra: Publicações EuropaAmérica, 1983.

BOURDIEU, Pierre. Coisas ditas. São Paulo: Brasiliense, 1990.

BOURDIEU, Pierre. Meditações pascalianas. Rio de Janeiro: Bertrand Brasil, 2001.

BURKE, Peter. A escrita da história: novas perspectivas. São Paulo: Editora UNESP, 1992.

CERTEAU, Michel de. A escrita da história. Rio de Janeiro: Forense Universitária, 1982.

CERTEAU, Michel de. A invenção do cotidiano: artes de fazer. Petrópolis, RJ: Vozes, 2004. 
CHARTIER, Roger. A história cultural: entre práticas e representações. 2.ed.. Rio de Janeiro: Difel, 1988.

CHARTIER, Roger. O mundo como representação. Estudos Avançados, São Paulo, v. 5, n.11, p. 173-1991 jan./abr. 1991.

COMTE, Auguste. Os pensadores. São Paulo: Abril Cultural, 1978.

FERREIRA NETO, Amarilio et al. Catálogo de periódicos de educação física e esportes (1930-2000). Vitória: Proteoria, 2002.

FERREIRA NETO, Amarilio. A pedagogia no exército e na escola: a educação física brasileira (1880-1950). Aracruz/ES: Facha, 1999.

GOELLNER, Silvana Vilodre. (Org.). Inezil Penna Marinho: coletânea de textos. Porto Alegre: Universidade Federal do Rio Grande do Sul, Colégio Brasileiro de Ciências do Esporte, 2005.

GOELLNER, Silvana Vilodre; SILVA, André Luiz dos Santos (Org.). Nos recônditos da memória: acervo pessoal de Inezil Penna Marinho. Porto Alegre: Gênese, 2009.

KARNAL, Leandro; TATSCH, Flavia Galli. A memória evanescente. In: PINSKY, Carla Bassanezi (Org.). Fontes históricas. São Paulo: Contexto, 2005. p. 9-27.

LACERDA, Gustavo Biscaia de. Augusto Comte e o "positivismo" redescobertos. Revista de Sociologia e Política, Curitiba, v. 17, n. 34, p. 319-343, out. 2009.

LE GOFF, Jacques. A história nova. 2. ed.. São Paulo: Martins Fontes, 1993.

LE GOFF, Jacques. História e memória. 5. ed.. Campinas, SP: Editora da UNICAMP, 2003.

MARINHO, Inezil Penna. Contribuição para a história da educação física no Brasil: Brasil Colônia - Brasil Império - Brasil República. Rio de Janeiro: Imprensa Nacional, 1943.

MARINHO, Inezil Penna. Dez mil classes para a educação de adultos. Revista Brasileira de Educação Física, Rio de Janeiro, v. 4, n. 35, p. 5, fev. 1947.

MARINHO, Inezil Penna. Discurso de posse de cátedra de História e Organização da Educação Física e Desportos. Arquivos da ENEFD, Rio de Janeiro, v. 11, n.12, p.127-144, dez.1958.

MARINHO, Inezil Penna. História da educação física no Brasil. Rio de Janeiro: Ministério da Educação e Saúde, Divisão de Educação Física, 1952-1954. v. 1-4.

MARINHO, Inezil Penna. Metodologia filosófica e científica aplicada à educação física e aos desportos. Brasília: Horizonte, 1972.

MARINHO, Inezil Penna. Rui Barbosa: o paladino da educação física no Brasil. 2. ed.. Brasília: Horizonte, 1980.

MELO, Victor Andrade de. Inezil Penna Marinho: notas bibliográficas. In: FERREIRA NETO, Amarílio. (Org.). Pesquisa histórica na educação física. Aracruz: Faculdade de Ciências Humanas de Aracruz, 1998. v. 3, p. 48-68.

NASCIMENTO, Célia Carvalho do. Inezil Penna Marinho: o tempo de uma história. In: FERREIRA NETO, Amarílio. (Org.). Pesquisa histórica na educação física. Vitória: Ufes, Centro de Educação Física e Desportos, 1997. v. 2, p. 121-156. 